\title{
Organic pollution and its effects: a short-term transplant experiment to assess the ability of biological endpoints to detect change in a soft sediment environment
}

\author{
Liz Morris*, Michael J. Keough \\ Department of Zoology, University of Melbourne, Victoria 3010, Australia
}

\begin{abstract}
A wide variety of endpoints or metrics are commonly employed in pollution monitoring situations but, to date, there have been very few experimental field studies aimed at assessing links between a putative pollutant and established soft sediment assemblages. We carried out a manipulative field experiment whereby intact assemblages were transplanted from control areas to sites adjacent to drains discharging secondary treated sewage effluent at 3 intertidal outfall locations in Port Phillip Bay, Victoria, Australia. We found that the ability of different measures to detect impacts varied, although multivariate methods were able to discriminate the effects of treatment, and population level measures tended to be more sensitive than assemblage level measures of abundance, biomass and diversity. Integrated measures, such as average individual biomass, were found to provide a sensitive detection tool plus an insight into the biological consequences of observed changes. We consider our findings in the light of conceptual models of pollution-induced change in soft sediment assemblages.
\end{abstract}

KEY WORDS: Benthic $\cdot$ Sewage $\cdot$ Pollution monitoring $\cdot$ Intertidal $\cdot$ Field experiment $\cdot$ Soft sediment Endpoint $\cdot$ Taxonomic distinctness

\section{INTRODUCTION}

A range of biological endpoints or metrics that summarize or incorporate population or assemblage level information is often employed in pollution monitoring studies (see Washington 1984, Burd 1990, Keough \& Quinn 1991, Warwick 1993 for reviews). It is generally agreed that these endpoints may differ in their ability to detect impacts and that these differences may be related to geographical area or to the composition of the purported pollutant (e.g. Ferraro et al. 1989, Warwick 1993). While there has been a considerable amount of attention directed at assessing the efficacy of various biological endpoints (e.g. Gray et al. 1990,

*E-mail: liz.morris@nre.vic.gov.au
Warwick \& Clarke 1991, Ferraro et al. 1994), there has also been a call for more experimental studies to test the proposed links between pollutants and changes in faunal assemblages (Warwick et al. 1988, Keough \& Quinn 1991, Gray 1992). To this end, mesocosms have been used as experimental test systems of responses to pollutants, for meiofauna (Warwick et al. 1988) and macrofauna (Oviatt et al. 1987, Gray et al 1988, Maughan \& Oviatt 1993). Manipulative field studies aimed at detecting links between a putative pollutant and established soft sediment assemblages are rarer; although Morrisey et al. (1996) investigated the effect of copper on macroinfaunal assemblages and Eleftheriou (1982) looked at the effects of dosing sediments with sewage sludge.

Often a problem with attributing assemblage change to the putative pollutant is that studies may be con- 
founded by environmental variables, such as sediment type, that influence assemblage structure. Alternatively a natural temporal disturbance such as a winter storm (Ferraro et al. 1991) may act on the assemblages in a similar way to a pollutant making it difficult to distinguish the actual cause of change. This latter type of influence may be considered a 'pulse' disturbance that confounds the effect of the long-term 'press' disturbance (Bender 1984). An ideal endpoint would be sensitive to changes in the pollutant but not to other influences, and respond to the pollutant in a consistent and predictable way.

The Pearson \& Rosenberg (1978) 'model' is still frequently used as a conceptual framework in soft sediment organic pollution monitoring studies (e.g. Ferraro et al. 1991, Maurer et al. 1993, Heip 1995). They proposed that changes in certain simple population and community level measures occurred with increasing organic pollution through either space or time. These changes are broadly summarized by an afaunal or severely polluted zone, a zone of stimulation or moderate organic input, and non-polluted or background conditions. Species richness, faunal abundance, and biomass are also described as changing between these zones in a predictable manner relative to each other; although there has been very little experimental evaluation of these predictions. Effective and sensitive monitoring programs require a knowledge of: (1) which endpoints are likely to respond to potential pollutants, and what is the direction and the magnitude of these responses; and (2) the appropriate time frame for monitoring. Often such information is not available on a site-specific, or even regional, basis.

The use of transplant experiments has a long history in experimental ecology although there are few reports in the recent published literature that we are aware of that describe transplanting intact assemblages of macrofauna in soft sediment systems across a pollution gradient (but see Lenihan et al. 1995, Negarestan 1998). Transplant experiments are particularly useful in soft sediment systems because, where transplantation takes place within a broadly similar physical regime, they allow sediment characteristics to be kept constant over the short term while exposing the animals to different water quality characteristics. They can also give an indication of the response time of fauna to changes in water quality.

We decided to use a short-term transplant experiment to answer the following questions: (1) How sensitive are selected endpoints in an experimental environment? (2) Do general ecological theory and available descriptive models allow us to predict how endpoints will change in relation to each other at several different locations? (3) Within what time frame should a sensitive monitoring program operate in this environment?

\section{MATERIALS AND METHODS}

Study area. This study was carried out at the Western Treatment Plant that covers 10851 ha, including approximately $20 \mathrm{~km}$ of foreshore over which 4 main drains discharge secondary treated effluent into Port Phillip Bay, Victoria, Australia. Two rivers (Werribee River and Little River) discharge into the bay immediately adjacent to, and within, the Western Treatment Plant. We carried out our experiments in the upper intertidal zone around 3 of the 4 operating drains at the plant: the Lake Borrie, the 145 West and the 15 East Drains. Table 1 presents water quality data from these 3 drains taken from the Melbourne Water Corporation environment and community obligation report 1998/1999.

Plume studies undertaken at the Western Treatment Plant have indicated that the transport and mixing of effluent plumes are very strongly influenced by wind (C. Pattiaratchi et al. unpubl.). Although the resolution of these studies tends to be at the scale of the whole treatment plant rather than individual outfalls. Studies of infaunal assemblages have generally concluded that there is an area of moderate impact up to several hundreds of metres from the discharge drains (Poore \& Kudenov 1978, Davies \& Brown 1995). There is also general agreement between these studies that an inshore area adjacent to the section of the plant that encompasses the 3 drains investigated in this study can be considered impacted to some degree, and periodic dumps of drift algae onto the foreshore exacerbate this in the intertidal.

Experimental transplants. At each outfall location 2 sites were chosen, one very close to the outfall (outfall site) and another at least $1 \mathrm{~km}$ away from the nearest outfall (control site). The control sites, while not typical unpolluted reference sites, provide background information for conditions across the Western Treatment Plant foreshore. It was not possible to find enough sites within the Western Treatment Plant to control for the effects of moving animals to a new location (Chapman 1999). We feel that by transplanting cores of mud to new positions within the control sites, we adequately addressed the problem of experimental artifacts resulting from the movement of sediment to a new area.

Intact assemblages were taken from control sites using a $9 \mathrm{~cm}$ diameter PVC pipe to a depth of $10 \mathrm{~cm}$ and capped immediately on removal from the sediment. These 'plugs' of sediment were placed in a cool box for transportation to their transplant positions. To transplant the assemblages, $9 \mathrm{~cm}$ diameter PVC pipes were placed inside a slightly larger outer 'sleeve' which in turn was surrounded by chicken wire, and this combination was pushed into the sediment at the 
randomly chosen transplant positions. The inner pipe was dug out to a depth of $10 \mathrm{~cm}$, and the sediment 'plug' to be transplanted was then placed in the hole. After which we removed the outer sleeve leaving the chicken wire in place, which ensured that exactly the same bit of sediment would be re-sampled while allowing animals to move in and out of the cores in any direction.

In February 1999, 4 replicates for each treatment and time combination were transplanted; the control cores were sampled from the control site and randomly allocated new positions within the control site while the outfall cores were transplanted from the control sites to the outfall sites. Pilot studies had indicated that using 4 replicate samples would provide adequate power for most measures. Four replicate samples were also taken from control sites at the beginning of the experiment to represent the pre-transplant conditions although they were not used in the subsequent analysis, as they were not subject to experimental treatments. Transplanted cores were sampled at $14 \mathrm{~d}$ intervals at all sites, although unfortunately, due to stormy weather causing sediment movement, we lost some of the chicken wire markers. This meant that the Lake Borrie sites were only sampled once (i.e. after 14 d) the 145 West sites were sampled after $14 \mathrm{~d}$ and again after $28 \mathrm{~d}$, and the 15 East sites were sampled after 14, 28 and $42 \mathrm{~d}$.

Laboratory processing. Samples were returned to the laboratory, sieved through a $0.5 \mathrm{~mm}$ sieve and preserved in $10 \%$ formaldehyde solution for later processing. We used a $0.5 \mathrm{~mm}$ sieve as opposed to a $1 \mathrm{~mm}$ sieve because our experience at this site indicated that the majority of animals would be adequately sampled with this sieve size. A 'Jones type' sample splitter was used to speed up the processing time and samples were split into 2 , before sorting under a dissecting microscope. Trials with the sample splitter had indicated that sorting half the sample gave very good estimates of abundance for the entire sample, and we have used whole sample estimates for all subsequent analysis. All animals were counted and identified to the lowest practicable level and biomass (wet weight after blotting) was recorded for each species group to the nearest $0.001 \mathrm{~g}$.

Choice of endpoints. A wide range of pollution endpoints has been proposed in the literature but for the purposes of this paper we decided to restrict ourselves to examining some very popular univariate measures (total abundance, total biomass, number of taxa, Shannon Wiener diversity index $H^{\prime}$ (using log e) and species richness as Margalef's $d$ ). Recently, a new biodiversity index has been proposed-the taxonomic distinctness $\left(\Delta^{*}\right)$ measure of Warwick \& Clarke (1995) - and this type of experimental investigation is an ideal opportunity to test this new index along with the more traditional measures. We have followed the methods for calculating $\Delta^{*}$ given in Warwick \& Clarke (1995) and used the taxonomic levels of species, genus, family, order, class and phylum weighted from 1 to 6 . Common taxa, that is, taxa that comprised over $1 \%$ of total faunal abundance at more than one of the locations, are assessed for their usefulness as indicator species. Very little information is available regarding the identification of oligochaetes in Australia, so no attempt was made to identify these worms further. A simple biomass:abundance (B:A) ratio within each common species group has been included because we predicted that the main effect of the outfalls would be to increase food availability and therefore

Table 1. Water quality data from 3 of the 4 existing outfalls used in this experiment (taken from the Melbourne Water Corporation Environment and Community Obligation Report 1998/1999, Melbourne 1999)

\begin{tabular}{|c|c|c|c|c|c|c|}
\hline \multirow[t]{2}{*}{ Variable } & \multicolumn{2}{|c|}{15 East } & \multicolumn{2}{|c|}{145 West } & \multicolumn{2}{|c|}{ Lake Borrie } \\
\hline & Median & Maximum & Median & Maximum & Median & Maximum \\
\hline Average daily discharge (megalitres) & $222^{\mathrm{a}}$ & & $62^{\mathrm{a}}$ & & $51^{\mathrm{a}}$ & \\
\hline $\operatorname{CBOD}\left(\mathrm{mg} \mathrm{l}^{-1}\right)$ & 5 & 31 & 14 & 38 & 8 & 22 \\
\hline BOD5 (mg l-1) & 17 & 150 & 21 & 80 & 11 & 44 \\
\hline Suspended solids $\left(\mathrm{mg} \mathrm{l}^{-1}\right)$ & 20 & 63 & 58 & 240 & 43 & 190 \\
\hline Ammonia as $\mathrm{N}\left(\mathrm{mg} \mathrm{l}^{-1}\right)$ & 1.2 & 33 & 12 & 30 & 19 & 25 \\
\hline Total nitrogen $\left(\mathrm{mg} \mathrm{l}^{-1}\right)$ & 24 & 71 & 24 & 71 & 25 & 40 \\
\hline Total phosphorous ( $\mathrm{mg} \mathrm{l}^{-1}$ ) & 10 & 11 & 10 & 11 & 12 & 17 \\
\hline Cadmium $\left(\mathrm{mg} \mathrm{l}^{-1}\right)$ & 0.0002 & 0.002 & 0.0005 & 0.002 & 0.0007 & 0.0027 \\
\hline Chromium $\left(\mathrm{mg} \mathrm{l}^{-1}\right)$ & 0.006 & 0.01 & 0.014 & 0.052 & 0.016 & 0.081 \\
\hline Copper $\left(\mathrm{mg} \mathrm{l}^{-1}\right)$ & 0.007 & 0.014 & 0.012 & 0.044 & 0.016 & 0.068 \\
\hline Lead $\left(\mathrm{mg} \mathrm{l}^{-1}\right)$ & 0.003 & 0.005 & 0.006 & 0.019 & 0.008 & 0.044 \\
\hline Mercury (mg l-1) & 0.0001 & 0.0001 & 0.0001 & 0.0003 & 0.0001 & 0.0005 \\
\hline Nickel $\left(\mathrm{mg} \mathrm{l}^{-1}\right)$ & 0.017 & 0.023 & 0.017 & 0.023 & 0.022 & 0.041 \\
\hline $\operatorname{Zinc}\left(\mathrm{mg} \mathrm{l}^{-1}\right)$ & 0.011 & 0.019 & 0.022 & 0.064 & 0.026 & 0.130 \\
\hline à Mean values & & & & & & \\
\hline
\end{tabular}


increase the size of individuals. Changes in this ratio may be brought about for a variety of reasons, but an increase in the B:A ratio indicates that, on average, individuals at that site are larger. A change to bigger organisms may be brought about by a shift to larger long-lived taxa at the assemblage level for example, or by increased growth or selective impacts on juveniles within species groups. While the reason for changes in this ratio may not be immediately obvious, the ratio can be equated to changes in average individual size either in the assemblage as a whole or within a species group. As multivariate measures are also very popular in pollution monitoring studies, we have included what we consider the most common of the available techniques, nonmetric multidimensional scaling.

Statistical analysis. Univariate analyses were done separately for each outfall location using 1- or 2-factor analysis of variance with treatment and time both as fixed factors. Data from the 2 wk sampling occasion were also analyzed together, again with location and treatment as fixed factors. Data was checked for normality and heterogeneity of variance using box and residual plots and raw data has been used in all cases. These analyses were done using SYSTAT Version 7 (SPSS Inc., Chicago, IL).

In the absence of significant effects of treatment or treatment $\times$ time interactions, we have calculated the

1a. Capitella sp.

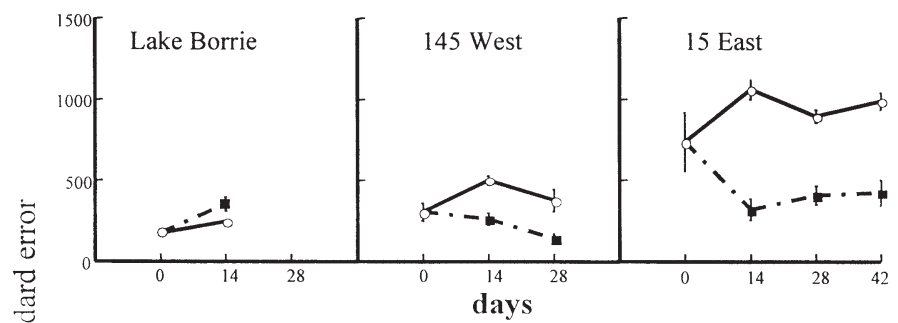

1c. Polydora sp.
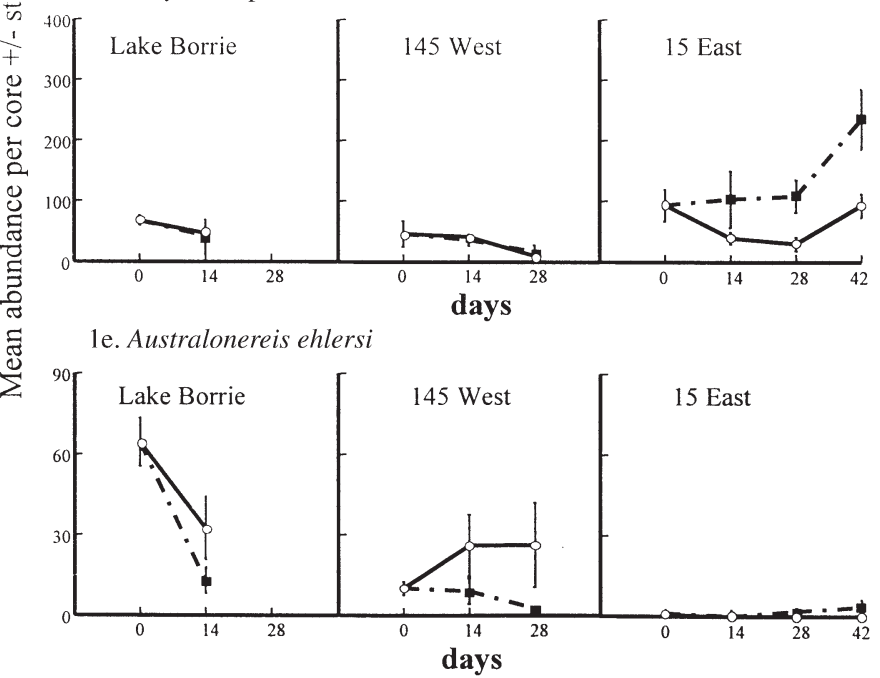

minimum detectable effect size (MDES) for population and assemblage level measures for $80 \%$ power. MDES values were calculated as the percentage change from control values pooled over time using the MS error term from the original ANOVA as the pooled estimate of variance. These power calculations were done using GPOWER (available at: www.psycho.uni-duesseldorf.de/ aap/projects/gpower).

Non-metric multidimensional scaling (nMDS) using Bray Curtis similarity measures was undertaken using the PRIMER Package. The ANOSIM procedure (Clarke 1993) provided in PRIMER was used to test for differences between outfalls and treatments.

\section{RESULTS}

A total of 34 taxa were recorded from all 3 locations during the course of the experiments. Polychaete worms and corophid amphipods numerically dominated all 3 locations. Bivalve molluscs were also common at the 145 West and 15 East locations. Estimates of total faunal abundance ranged from 72966 to $363769 \mathrm{~m}^{-2}$. Only 8 taxa occurred at more than one of the outfall locations in numbers large enough to analyze for the population measures. All taxa at each location were included in the univariate mea-

1b. Boccardia proboscidea

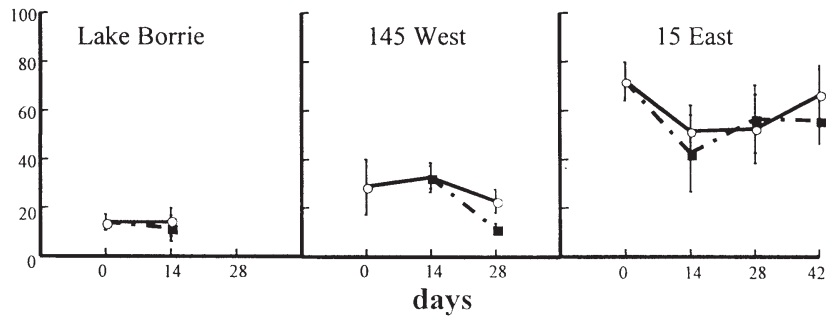

1d. Simplisetia aequisetis

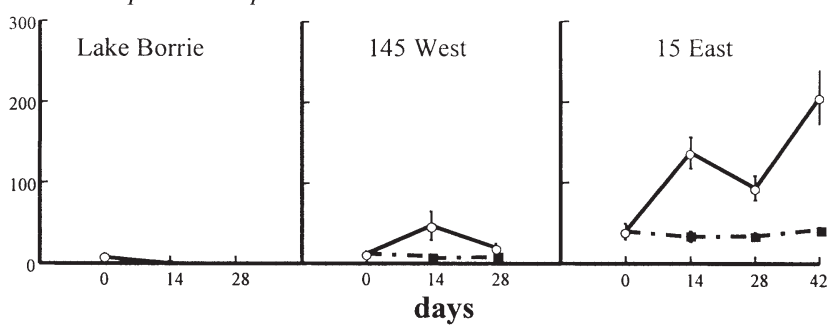

Legend

$\longrightarrow$ Control Treatment

$\rightarrow$ Outfall Treatment

Fig. 1. Mean abundance per core $( \pm S E)$ of polychaete taxa following transplantation within a control site, or between a control and an outfall site at 3 outfall locations; Lake Borrie, 145 West and 15 East 
Table 2. $\mathrm{p}$-values from ANOVAS for the 3 experimental locations. Bold indicates statistical significance at $\mathrm{p}<0.05$ (n $=4$ ). Minimum detectable effect sizes (MDES) for a power of 0.8 have been calculated for population and assemblage measures in the absence of significant treatment or treatment $\times$ time interactions and are expressed as \% change from the control cores pooled over time

\begin{tabular}{|c|c|c|c|c|c|c|c|c|c|c|}
\hline & \multicolumn{2}{|c|}{ - Lake Borrie - } & \multicolumn{4}{|c|}{-145 West -} & \multicolumn{4}{|c|}{15 East } \\
\hline & $\begin{array}{l}\text { Treat } \\
(\mathrm{df}=1)\end{array}$ & $\begin{array}{c}\text { MDES } \\
(\%)\end{array}$ & $\begin{array}{l}\text { Treat } \\
(\mathrm{df}=1)\end{array}$ & $\begin{array}{l}\text { Time } \\
(\mathrm{d} \mathrm{f}=1)\end{array}$ & $\begin{array}{l}\text { Treat } \times \\
\text { Time } \\
(\mathrm{df}=1)\end{array}$ & $\begin{array}{c}\text { MDES } \\
(\%)\end{array}$ & $\begin{array}{l}\text { Treat } \\
(\mathrm{df}=1)\end{array}$ & $\begin{array}{l}\text { Time } \\
(\mathrm{df}=2)\end{array}$ & $\begin{array}{l}\text { Treat } \times \\
\text { Time } \\
(\mathrm{df}=2)\end{array}$ & $\begin{array}{c}\text { MDES } \\
(\%)\end{array}$ \\
\hline \multicolumn{11}{|l|}{ Population measures } \\
\hline Capitella sp. & 0.026 & & $<0.001$ & 0.009 & 0.966 & & $<0.001$ & 0.549 & 0.061 & \\
\hline Boccardia proboscidea & 0.718 & 161 & 0.161 & 0.002 & 0.172 & 43 & 0.564 & 0.433 & 0.763 & 45 \\
\hline Polydora sp. & 0.832 & 179 & 0.953 & 0.007 & 0.428 & 93 & $<0.001$ & 0.003 & 0.309 & \\
\hline Simplisetia aequisetis & 0.356 & 333 & 0.002 & 0.047 & 0.035 & & $<0.001$ & 0.002 & 0.007 & \\
\hline Australonereis ehlersi & 0.115 & 111 & 0.030 & 0.710 & 0.688 & & 0.032 & 0.219 & 0.219 & \\
\hline Oligochaetes & 0.268 & 161 & 0.003 & 0.111 & 0.088 & & 0.001 & 0.045 & 0.492 & \\
\hline Corophium insidiosum & 0.004 & & 0.012 & 0.162 & 0.810 & & 0.232 & 0.294 & 0.006 & \\
\hline \multicolumn{10}{|l|}{ Assemblage measures } & 54 \\
\hline Total abundance & 0.002 & & 0.001 & 0.951 & 0.764 & & $<0.001$ & 0.066 & 0.015 & \\
\hline Total biomass & 0.093 & & 0.680 & 0.911 & 0.027 & & 0.462 & 0.028 & 0.702 & 29 \\
\hline Total taxa & 0.007 & & 0.310 & 0.144 & 0.349 & 28 & 0.060 & 0.024 & 0.344 & 14 \\
\hline Margalef's $d$ & 0.014 & & 0.034 & 0.118 & 0.275 & & $<0.001$ & 0.031 & 0.036 & \\
\hline Diversity $H^{\prime}$ & 0.027 & & 0.001 & 0.092 & 0.429 & & $<0.001$ & $<0.001$ & $<0.001$ & \\
\hline Taxonomic distinctness $\Delta^{*}$ & 0.011 & & 0.011 & 0.020 & 0.973 & & 0.492 & 0.077 & $<0.001$ & \\
\hline \multicolumn{11}{|l|}{ Biomass:abundance ratios } \\
\hline Total B:A & 0.018 & & 0.024 & 0.321 & 0.111 & & $<0.001$ & 0.017 & $<0.001$ & \\
\hline Capitella sp. & 0.010 & & $<0.001$ & $<0.001$ & $<0.001$ & & 0.001 & 0.603 & 0.327 & \\
\hline B. proboscidea & 0.001 & & 0.585 & 0.616 & 0.075 & & 0.004 & 0.017 & 0.465 & \\
\hline Polydora sp. & 0.033 & & 0.005 & 0.307 & 0.279 & & 0.002 & 0.046 & 0.092 & \\
\hline S. aequisetis & 0.356 & & 0.394 & 0.660 & 0.042 & & $<0.001$ & 0.250 & 0.155 & \\
\hline A. ehlersi & 0.174 & & 0.081 & 0.006 & 0.095 & & 0.245 & 0.379 & 0.379 & \\
\hline Oligochaete & 0.815 & & 0.741 & 0.621 & 0.897 & & 0.221 & 0.858 & 0.212 & \\
\hline C. insidiosum & 0.964 & & 0.009 & 0.316 & 0.380 & & $<0.001$ & 0.225 & 0.330 & \\
\hline M. semiradiata & 0.003 & & 0.207 & 0.607 & 0.207 & & 0.069 & 0.419 & 0.320 & \\
\hline
\end{tabular}

sures of abundance, biomass and diversity, and the multivariate measures.

\section{Population level measures}

In these experiments the polychaetes showed a range of responses to the experimental treatment both within and between outfall locations. Capitella sp. changed in abundance at all 3 locations (Fig. 1a, Table 2), increasing in abundance at the Lake Borrie outfall site when compared to the control site and showing the opposite pattern at the 145 West and 15 East outfall sites. Of the 2 spionid polychaetes presented here, Boccardia proboscidea tended to be less abundant at the Lake Borrie location but did not change significantly in abundance with experimental treatment at any of the locations (Fig. 1b, Table 2). Polydora sp. showed changes in mean abundance with time at both 145 West and 15 East. The only response of Polydora sp. with treatment occurred at the 15 East location, where the outfall cores had higher numbers of Polydora sp. than the control cores at all 3 times. Where there were no apparent changes in abundance for these spionids, we could have detected, with $80 \%$ confidence, changes in the outfall cores of between 93 and $179 \%$ of the control cores. The 2 nereid species, Simplisetia aequisetis and Australoneris ehlersi showed no change in abundance when transplanted to the outfall site at Lake Borrie compared to the control site (Fig. 1d,e). A. ehlersi, however, did decrease in abundance at the outfall site at the 145 West location and $S$. aequisetis occurred in lower numbers in the outfall cores when compared to the control cores at all times for both the 145 West and 15 East locations. Interestingly, at both these locations there were fluctuations in the abundance of $S$. aequisetis in the control cores while numbers in the outfall cores remained fairly consistent.

Of the 3 other taxa presented in Fig. 2, once again there is a range of responses demonstrated both within and between outfall locations. The oligochaete worms occurred in much lower densities at the 145 West location (Fig. 2a) so the increase in abundance in 
the outfall cores compared to the control cores should be treated with some caution (Table 2). No change in oligochaete numbers with treatment was observed at the Lake Borrie location, but at 15 East oligochaete numbers were consistently lower in the outfall cores than the control cores. The bivalve Montacuta occurred in low densities at the Lake Borrie location (Fig. 2c), increased in abundance in the outfall cores compared to the control cores at 145 West and did not vary between treatments at 15 East. The corophid amphipod Corophium insidiosum was abundant at all locations and showed large increases at all 3 control sites between Time 0 (samples taken pre-transplantation) and Time 1, $14 \mathrm{~d}$ later (Fig. 2b). This species showed decreases in abundance in outfall cores when compared to control cores at both Lake Borrie and 145 West locations while at 15 East a more complex response was apparent. Examination of the interaction plot (Fig. 2b) shows that an initial decrease in $C$. insidiosum in the outfall cores after $14 \mathrm{~d}$ is followed by an increase in the outfall cores and a decrease in the control cores after $28 \mathrm{~d}$. By $42 \mathrm{~d}$ there is no difference in the abundance of $C$. insidiosum between the control and outfall cores.

In general, where population level responses are evident at the 15 East location, which has the biggest average daily discharge, they appear to be of greater magnitude than at the other locations (Figs $1 \& 2$ ).

\section{Abundance and biomass measures}

The various abundance and biomass measures show a range of responses with transplantation to an outfall

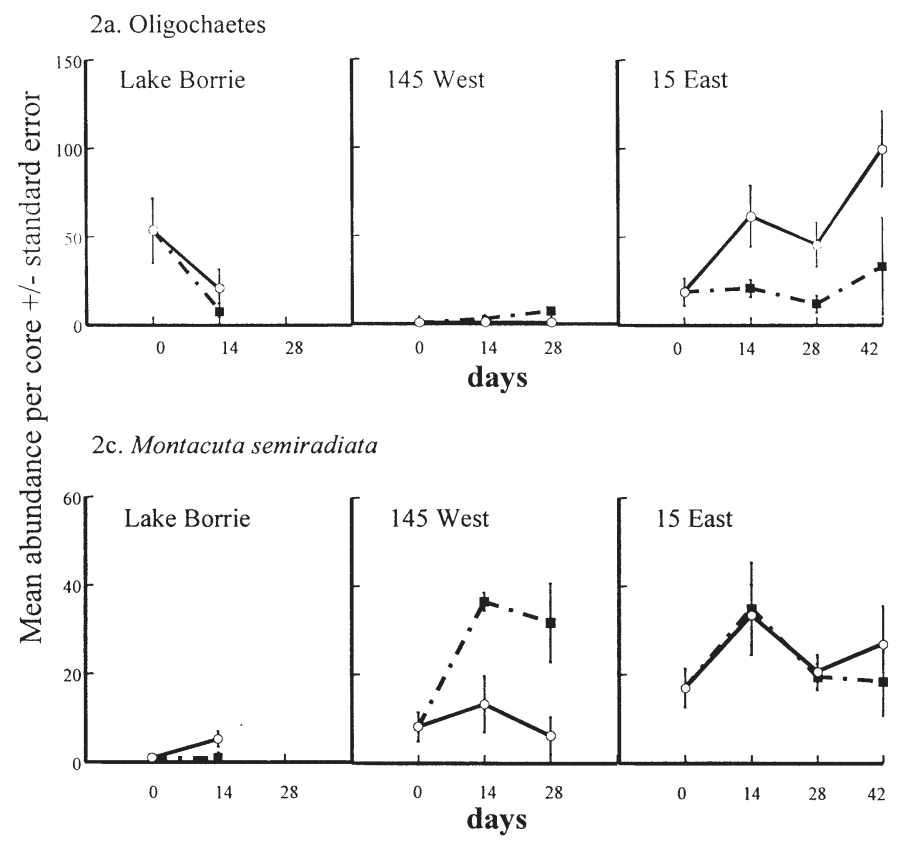

site and, as with the population measures, the responses tend to be inconsistent across the 3 locations. Total faunal abundance decreased in the outfall cores at Lake Borrie and 145 West, and initially decreased in the outfall cores at 15 East. However, after $28 \mathrm{~d}$ there was no difference between the 2 treatments at this location (Fig. 3a). All 3 locations showed an initial increase in total abundance at the control site between Time 0 and Time 1 . The amphipod Corophium insidiosum, which was an important constituent of the assemblages at all 3 locations, was primarily responsible for this and also for the patterns observed in total abundance at 15 East. No changes in total biomass were detected at any of the locations for the main effect of treatment (Table 2, Fig. 3b). Furthermore, with an $80 \%$ power we would have been able to detect differences of 14 to $132 \%$ of the control cores. Total biomass:abundance ratios increased at all 3 outfall sites when compared to the control sites (Table 2, Fig. 3).

\section{Diversity measures}

Number of taxa was similar at all locations although only at Lake Borrie was a difference between control and outfall cores detected (Fig. 4a). At the other 2 locations, we could have detected differences of 2 or 3 taxa from the control cores with $80 \%$ confidence. Species richness as measured by Magarlef's $d$ did, however, show responses at all locations (Fig. 4b). This index decreased in the Lake Borrie outfall cores, increased in the 145 West outfall cores and initially increased in the 15 East outfall cores, but again by Time 2 there was no difference
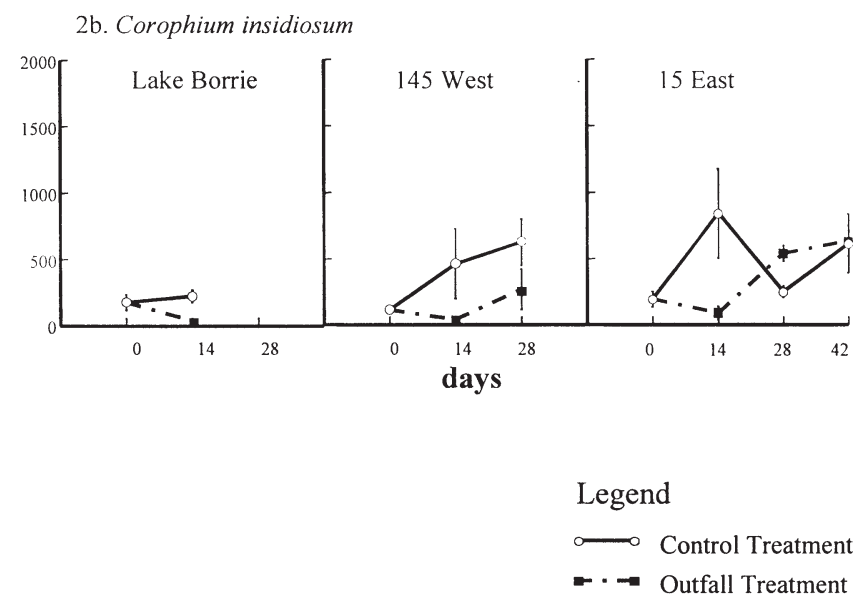

Fig. 2. Mean abundance per core $( \pm \mathrm{SE})$ of selected taxa following transplantation within a control site, or between a control and an outfall site at 3 outfall locations; Lake Borrie, 145 West and 15 East 
3a. Total abundance

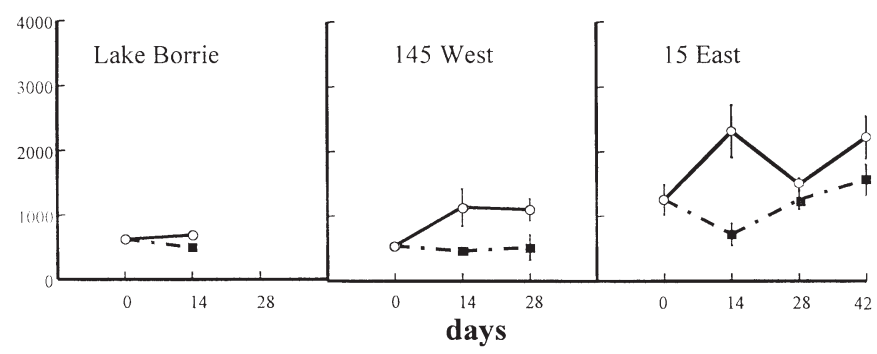

3c. Biomass / Abundance Ratio (mg)

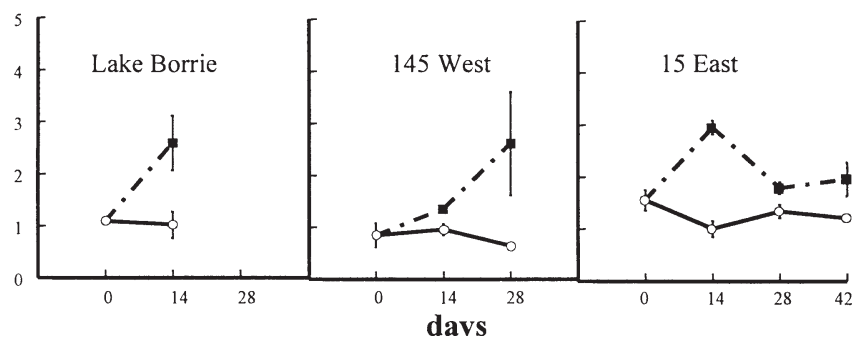

between control or outfall cores at this location. Similar patterns were observed with the Shannon Wiener diversity index, $H^{\prime}$ (Fig. 4c). The biodiversity index of taxonomic distinctness showed similar patterns to the other diversity measures at Lake Borrie whilst at 145 West and 15 East the pattern was almost opposite (Fig. 4 d, Table 2). At 145 West, the control cores had a higher taxonomic distinctness than the outfall cores after $28 \mathrm{~d}$; whereas at 15 East, a strong interaction between treatment and time was evident (Table 2). Initially, control assemblages increased biodiversity while outfall assemblages remained similar and then after $28 \mathrm{~d}$ this pattern was reversed and

4a. Total taxa

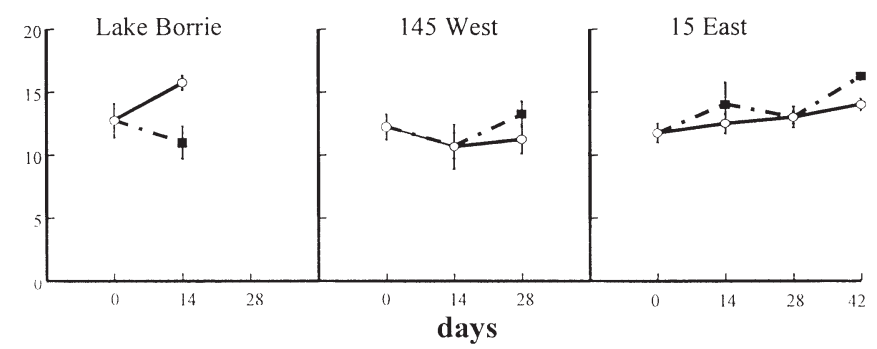

4c. Diversity (H')

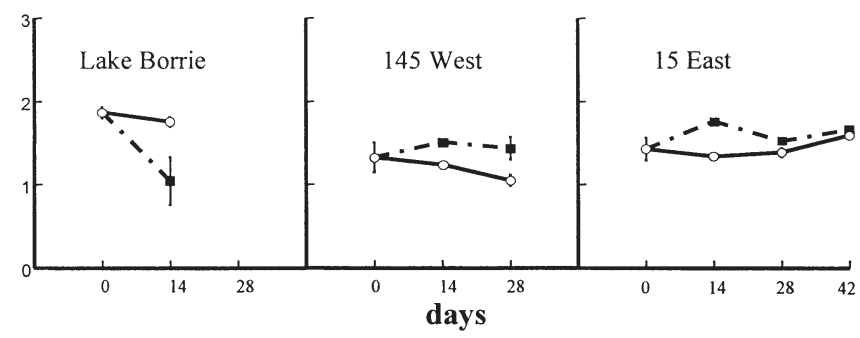

3b. Total biomass (g)

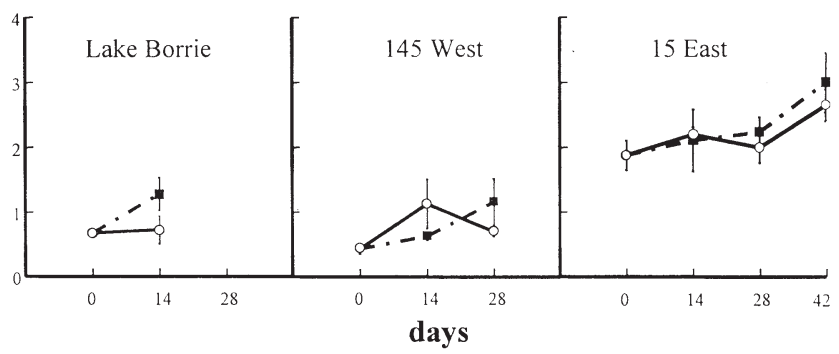

Legend

$\multimap$ Control Treatment

$\rightarrow$ Outfall Treatment

Fig. 3. Summary assemblage measures. Mean values per core $( \pm \mathrm{SE})$ following transplantation within a control site, or between a control and an outfall site at 3 outfall locations; Lake Borrie, 145 West and 15 East

by $42 \mathrm{~d}$ there appeared to be little difference in taxonomic distinctness between the 2 treatments.

\section{Average individual biomass}

Not all of the taxa presented in the previous section showed significant changes in average individual biomass but, with only one exception, where we did detect changes we found that animals in the outfall cores had larger body sizes than those in the control cores (Table 3).

4b. Species richness (d)

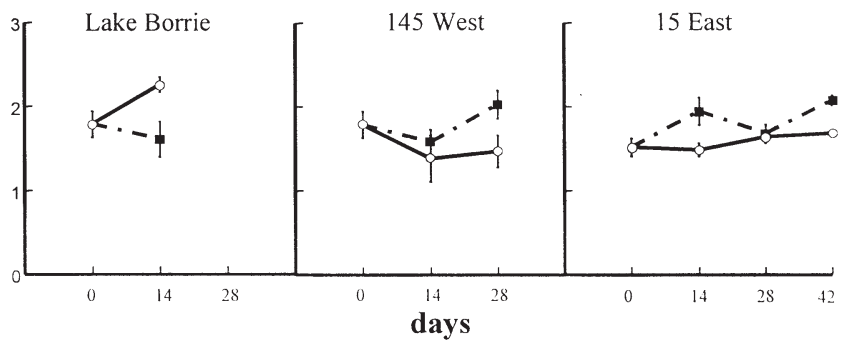

4d. Taxonomic distinctness $\left(\Delta^{*}\right)$

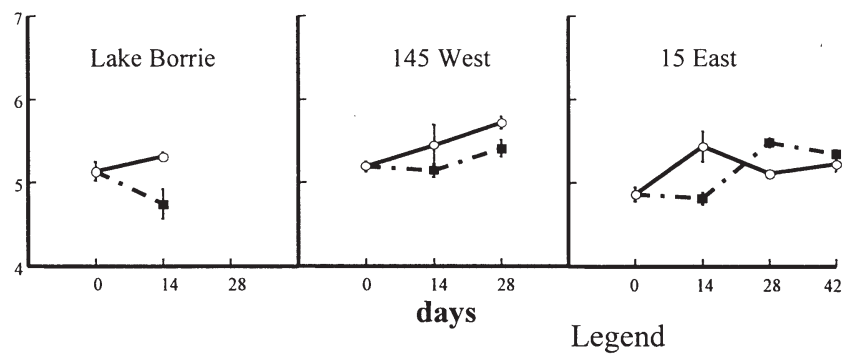

Legend
Fig. 4. Diversity measures. Mean values per core $( \pm \mathrm{SE})$ following transplantation within a control site, orbetween a control and an outfall site at 3 outfall locations; Lake Borrie, 145 West and 15 East $\longrightarrow$ Control Treatment - Outfall Treatment 


\section{Two week data}

Using just the 2 wk data allows the outfall locations to be used as replicates in 1 analysis and it is obvious that most of the measures differ between locations (Table 4). The population measures appear more sensitive than the assemblage measures for detecting the main effect of treatment mainly because of the interactions masking any effect of treatment for the diversity indices. An exception to this was the measure of taxonomic distinctness, which showed a significant effect of treatment, because after $2 \mathrm{wk}$ taxonomic distinctness was higher in the control cores than the outfall cores at all 3 locations. The total biomass:abundance ratio and the average individual biomass of polychaetes appeared to be sensitive measures for detecting impacts within this short time frame although several significant interaction terms indicate that slightly different patterns of change were evident at the different locations (Fig. 3c). These location $\times$ treatment interactions were generally the result of biomass : abundance ratios being slower to detect impacts at the 145 West location and so in the $2 \mathrm{wk}$ analysis differences at this location were not apparent.

\section{Multivariate analyses}

The analysis of similarities (ANOSIM) indicated significant differences between locations in a 2-way crossed model $(\mathrm{p}<0.001)$. Ordination plots following nMDS for 4 th root transformed abundance and bio- mass data are presented in Fig. 5; all samples, with all times and all locations are shown on each plot. There was also a significant effect of treatment $(p<0.001)$ and the ordination plots also indicate a separation of treatments within each location with outfall cores tending to be on one side of the control cores. A 4 th root transform has the effect of reducing the effect of the dominant taxa and increasing the importance of rare taxa, which can make a considerable difference to the analysis (e.g. Olsgard et al. 1997, 1998). However, in this study, untransformed data (patterns driven by dominant taxa) produced similar patterns to the plot presented here. Surprisingly, it has often been found that biomass and abundance data will result in similar ordination plots following nMDS despite the fact that different taxa will be driving the observed patterns (Warwick 1993) and this has shown to be the case here as well. Ordinations of aggregated taxa also gave similar patterns to those shown here for both biomass and abundance data. This provides support for recent studies which have found that pollution can be detected using a lower taxonomic level (e.g. Morrisey et al. 1996, Olsgard et al. 1998).

\section{DISCUSSION}

The ability of the different methods to detect treatment effects within the time frame of this study varied both within and between outfall locations. Other studies have also reported differential sensitivity in a range of endpoints (e.g. Ferraro et al. 1989, 1994, Ferraro \&
Abundance data - 4th root transform

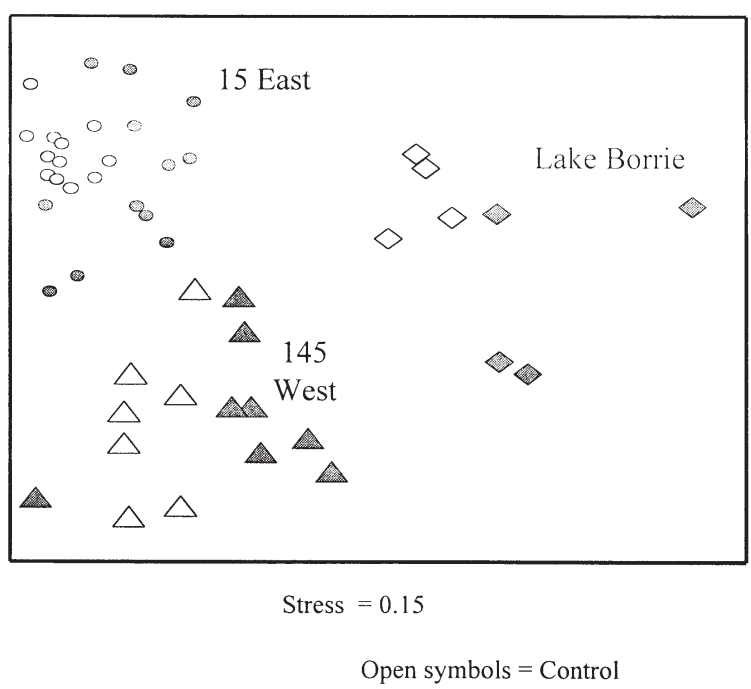

Biomass data - 4 th root transform

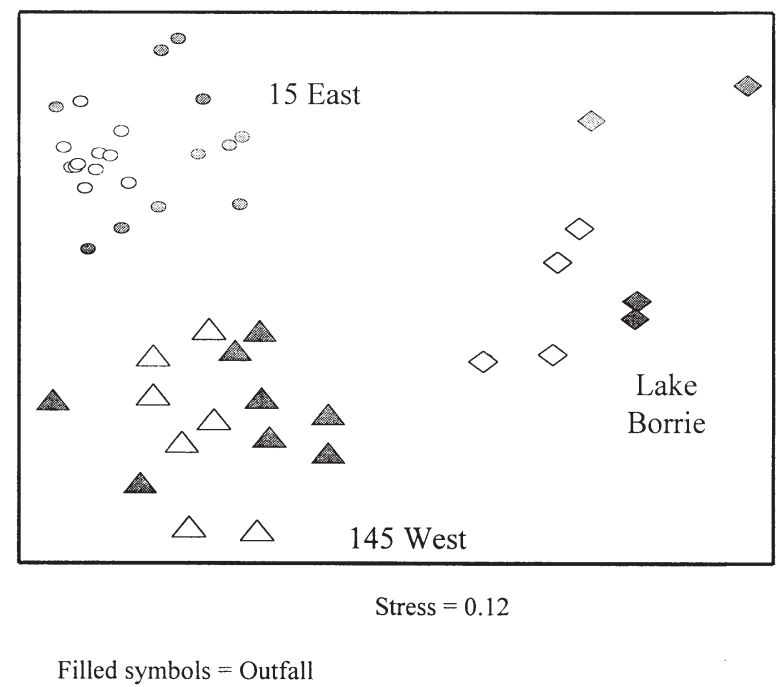

Fig. 5. nMDS plots of assemblages at 3 locations following transplantation. Plots do not include original background samples (i.e. Time 0) but include all other sampling times. Control treatments are shown in white and outfall treatments are shown in gray. $\mathrm{n}=3$ for 145 West control treatment at Time 1 (after $14 \mathrm{~d}$ ) and $\mathrm{n}=4$ for all other times 
Table 3. Mean values $( \pm \mathrm{SD})$ of average individual biomass $(\mathrm{mg})$ or biomass:abundance $(\mathrm{B}: \mathrm{A})$ ratios for selected taxa. Values are pooled over time and so represent the main effect of treatment in the corresponding ANOVA of Table 2

\begin{tabular}{|lcccccc|}
\hline \multirow{2}{*}{$\begin{array}{l}\text { Biomass : abundance } \\
\text { ratios }\end{array}$} & \multicolumn{2}{c}{ Lake Borrie } & \multicolumn{2}{c}{145 West } & \multicolumn{2}{c|}{15 East } \\
& Control & Outfall & Control & Outfall & Control & Outfall \\
\hline Capitella sp. & $0.407(0.112)$ & $0.609(0.263)$ & $0.482(0.285)$ & $0.757(0.363)$ & $0.674(0.137)$ & $0.844(0.143)$ \\
Boccardia proboscidea & $1.163(1.019)$ & $2.500(1.095)$ & $1.535(0.501)$ & $2.264(1.351)$ & $3.255(1.350)$ & $5.347(3.313)$ \\
Polydora sp. & $0.442(0.291)$ & $0.691(0.263)$ & $0.995(0.553)$ & $1.763(0.685)$ & $0.465(0.155)$ & $0.809(0.474)$ \\
Simplisetia aequisetis & $1.728(4.558)$ & $0.103(0.178)$ & $4.035(5.167)$ & $5.791(4.238)$ & $6.138(4.456)$ & $13.874(4.797)$ \\
Australonereis ehlersi & $3.145(1.921)$ & $2.357(2.110)$ & $4.635(1.903)$ & $6.210(4.406)$ & $0.187(0.544)$ & $11.419(37.609)$ \\
Oligochaete & $0.316(0.127)$ & $0.303(0.135)$ & $0.273(0.467)$ & $0.328(0.356)$ & $0.435(0.101)$ & $0.394(0.141)$ \\
Corophium insidiosum & $0.376(0.163)$ & $0.380(0.191)$ & $0.358(0.073)$ & $0.456(0.117)$ & $0.312(0.072)$ & $0.406(0.126$ \\
Montacuta semiradiata & $3.257(2.483)$ & $1.437(2.470)$ & $5.962(2.819)$ & $8.504(7.151)$ & $2.754(1.295)$ & $7.096(9.212)$ \\
& & & & & & \\
\hline
\end{tabular}

Cole 1990, Gray et al. 1990, Keough \& Quinn 1991, Warwick \& Clark 1991). Many of these authors also pointed out that the sensitivity of the different measures may not be globally applicable; changing with both location and habitat and also potentially with the components of the purported pollutant (see also Warwick 1993). It is obviously important to know which endpoints are sensitive to changes in water quality within a given geographical area and which are not in order to enable effective monitoring of the extent and severity of an impact or disturbance (Ferraro \& Cole 1995).

Polychaetes are common constituents of estuarine fauna and many, like Capitella sp. have been described as opportunistic taxa that increase in abundance with increasing organic pollution (Grassle \& Grassle 1974, Pearson \& Rosenberg 1978, Tsutsumi 1987, 1990). In this study, the polychaetes appeared to have potential as indicator species, at least in terms of sensitivity, as changes in abundance following transplantation to an outfall site were frequently recorded at all 3 locations (Table 2). We might have predicted differences in the magnitude of change amongst the different polychaete taxa depending on their tolerance to pollution. While there were no consistent differences between taxa, there appeared to be an effect of discharge. The largest change occurred at the 15 East location with a mean increase in abundance of Polydora sp. of $175 \%$ following transplantation to an outfall site. This taxon showed no change in abundance at the other locations, but where responses to transplantation were observed in other taxa at the 145 West and Lake Borrie locations, the magnitude of change ranged from between 30 and $78 \%$ of the control cores. The discharge at 15 East is considerably larger than the other 2 locations and this may have been an important factor in the magnitude of responses observed. Members of the opportunistic Polydora complex, including Polydora sp. and Boccardia sp., are often associated with organically enriched situations (Pearson \& Rosenberg 1978). In particular Boccardia proboscidea has been proposed as an ideal indicator of organic pollution in south east Australia as this introduced species

Table 4. p-values from 2-factor ANOVA from 2 wk data with 3 locations and 2 treatments. Bold indicates significance statistical at $\mathrm{p}<0.05$

\begin{tabular}{|c|c|c|c|}
\hline & $\begin{array}{l}\text { Location } \\
(\mathrm{df}=2)\end{array}$ & $\begin{array}{l}\text { Treatment } \\
\qquad(\mathrm{df}=1)\end{array}$ & $\begin{array}{l}\text { Location } \times \text { Treatment } \\
\qquad(\mathrm{df}=2)\end{array}$ \\
\hline \multicolumn{4}{|l|}{ Population measures } \\
\hline Capitella sp. & $<0.001$ & $<0.001$ & $<0.001$ \\
\hline Boccardia proboscidea & 0.001 & 0.549 & 0.843 \\
\hline Polydora sp. & 0.253 & 0.311 & 0.171 \\
\hline Simplisetia aequisetis & $<0.001$ & $<0.001$ & $<0.001$ \\
\hline Australonereis ehlersi & 0.002 & 0.016 & 0.179 \\
\hline Oligochaete & $<0.001$ & 0.017 & 0.038 \\
\hline Corophium insidiosum & 0.069 & 0.001 & 2.235 \\
\hline Montacuta semiradiata & $<0.001$ & 0.105 & 0.033 \\
\hline \multicolumn{4}{|l|}{ Assemblage measures } \\
\hline Total abundance & $<0.001$ & $<0.001$ & 0.002 \\
\hline Total biomass & $<0.001$ & 0.953 & 0.105 \\
\hline Total taxa & 0.035 & 0.223 & 0.015 \\
\hline Margalef's $d$ & 0.014 & 0.969 & 0.001 \\
\hline Diversity $H^{\prime}$ & 0.248 & 0.944 & $<0.001$ \\
\hline Taxonomic distinctness $\Delta^{*}$ & 0.107 & $<0.001$ & 0.373 \\
\hline \multicolumn{4}{|l|}{ Biomass:abundance ratios } \\
\hline Total B:A & 0.006 & $<0.001$ & 0.010 \\
\hline Capitella sp. & 0.002 & $<0.001$ & 0.189 \\
\hline B. proboscidea & 0.003 & $<0.001$ & 0.011 \\
\hline Polydora sp. & 0.005 & 0.001 & 0.657 \\
\hline S. aequisetis & 0.006 & 0.252 & 0.004 \\
\hline A. ehlersi & $<0.001$ & 0.481 & 0.526 \\
\hline Oligochaete & 0.884 & 0.831 & 0.686 \\
\hline C. insidiosum & 0.203 & 0.148 & 0.539 \\
\hline M. semiradiataa & $<0.001$ & 0.165 & $<0.001$ \\
\hline
\end{tabular}


has a distribution restricted to areas in the direct influence of sewage discharges (Petch 1989). Consequently it is interesting to note that this short-term field manipulation did not identify Boccardia proboscidea as being particularly sensitive to changes in water quality. Power analyses indicated that we could have detected changes of between 43 and $161 \%$ in the number of worms in the control cores with $80 \%$ confidence, which is similar to the range of changes we saw in other taxa. Very little information exists regarding biologically important effect sizes (Fairweather 1991, Ferraro et al. 1994, Underwood 1996). However, these worms have been recorded in enormous numbers within the Western Treatment Plant intertidal region (e.g. up to 350000 worms $\mathrm{m}^{-2}$, Petch 1989) so we consider an ability to detect changes of up to 26 worms core $^{-1}$ or 4086 worms $\mathrm{m}^{-2}$ to be a reasonably powerful test in this case.

Of the remaining taxa examined, the oligochaete worms and the bivalve Montacuta showed varying responses between outfall locations. The amphipod Corophium insidiosum, on the other hand, did show a significant treatment effect in the 2 wk analysis (Table 3 ) but examination of the 3 locations separately (Fig. 2b, Table 2) showed that this amphipod changed in abundance with both treatment and time. The large and rapid changes in abundance observed in this study indicate that it is a very mobile and sensitive species that will respond quickly to other influences, such as natural pulses of nutrients across the shore, or indirect effects resulting from the responses of other taxa to the discharges, as well as to treatment effects. Certainly Corophium spp. have been used in both behavioral and ecotoxicological studies (e.g. Bat \& Raffaelli 1998, T. Stokie unpubl.); however, in the more variable field environment it appears less suitable as an indicator species.

The assemblage level measures of abundance, biomass and diversity tended to be less sensitive or less able to detect treatment effects in the short term than the population level measures (Table 3). These summary measures are very popular in monitoring studies, mainly because they allow a reduction of large data sets to single numbers amenable to statistical testing. Although the abundance and diversity measures responded to treatment effects at all locations, these changes were very much driven by changes in the abundance of the dominant taxa, Capitella sp. and Corophium insidiosum.

Of particular interest are the different patterns observed with the conventional diversity measures and the measure of taxonomic distinctness. Warwick \& Clarke (1995) suggested that the measure of taxonomic distinctness was more sensitive than conventional diversity measures at detecting stress. Although
Somerfield et al. (1997) concluded that this was not always the case and they did not observe any consistent pattern of decreasing taxonomic distinctness with increasing stress. We found no differences in sensitivity between traditional measures of diversity and taxonomic distinctness in the present study, but we did observe differences in the patterns of change. Other studies have found the biodiversity measure to track other measures of diversity quite closely even though the measure of taxonomic distinctness incorporates a different aspect of biodiversity into the calculation (Hall \& Greenstreet 1998, Rogers et al. 1999). Taxonomic distinctness $\left(\Delta^{*}\right)$ is a measure of the average path length between 2 individuals of different species and so where the assemblage is very much dominated by 2 species, as in this study, it is the relationship of these species that will drive the observed responses. In this case, it is very much the changes in abundance of Corophium insidiosum that are responsible for the observed patterns (see Figs $2 \mathrm{~b} \& 4 \mathrm{~d}$ ), and this is because the 2 dominant taxa in this study are in different phyla and so changes in abundance of these 2 taxa have a high weighting. The use of an index of taxonomic distinctness in this context is based on the assumption that in stressed situations the dominant taxa would be closely related (i.e. sibling species of Capitella or species of the Polydora complex; Warwick \& Clarke 1995), but in estuarine situations it is quite usual to find deposit feeding corophiid amphipods co-dominant with polychaetes. Consequently, the extreme sensitivity of this index to changes in abundance of a dominant species such as we observed here might be particular to estuarine situations. The use of different weighting factors for estuarine fauna is an option for reducing the dependence on dominant taxa of this index, and such an approach could be investigated with a much larger database than is available here.

The total biomass:abundance ratio was the only really sensitive and consistent assemblage measure in this study with increases in overall size recorded at all outfalls. This response fits our original prediction that the main effect of transplanting assemblages into an area in close proximity to an outfall would be to increase food supply and so increase the size of the animals present.

J. S. Gray and co-workers (Gray 1989, Gray et al. 1990) suggest that changes in the common measures of opportunists, abundance, total taxa and diversity, represent end points in a polluting sequence, rather than first effects or an early warning of potentially polluting impacts. Both historically (Dauer \& Conner 1980) and more recently there has been a suggestion that changes in intraspecific size distributions may be more relevant and interesting measures of potential stress 
(Weston 1990, Maurer et al. 1993). Work on life history strategies of opportunistic taxa suggest that changes in average individual size within a species group may have important consequences to population growth through reducing time taken to reach maturity and increased fecundity (Bridges et al. 1994, Bridges 1996, Levin et al. 1996). Changes in size may result from an increase in growth rates, or alternatively, energy may be converted directly to eggs and sperm, and so changes in B:A ratios may result from increases in reproductive material. While we do not have the information to determine the pathway of change in this study, the outcome for populations is likely to be similar. In this study, average individual biomass tended to be larger in the outfall cores when compared to the control cores in at least half of the taxa examined (Fig. 3, Tables $2 \& 4$ ). For certain taxa such as the Polydora complex, this measure proved much more sensitive than the abundance measures. In this case, rather than representing an end point of population change, it is an indicator of increased growth with its associated life history implications. Simplisetia aequisetis, on the other hand, had lower abundances in the outfall cores than the control cores (Fig. 1d) while individual biomass increased. This implies that the difference was due to changes in abundance of smaller individuals. Examination of the raw data indicates that while juvenile nereids were arriving at the control cores, they were not arriving at the outfall cores which suggests that different life history stages are differentially affected by the sewage effluent. For the amphipod Corophium insidiosum the large fluctuations with time were not observed in the measure of individual size as they were with a measure of abundance. Therefore, while this very mobile species will reflect pulse events in changes in abundance a more integral measure such as average individual size appears to respond only to the press event of increased proximity to an outfall.

Empirical evidence also suggests that total biomass:abundance ratios will decrease with increasing perturbation (Pearson \& Rosenberg 1978) although this was not the case in this study. Warwick (1986) suggests that this change is usually observed as the larger longlived taxa are replaced by smaller species with more opportunistic life history strategies. In this study, we did not see this shift to dominance by smaller species groups but, instead, an increase in overall size as food availability is increased close to the outfalls. If food availability were solely responsible for changes in population and assemblage level measures, we would also have predicted changes in biomass:abundance ratios to be more pronounced at the largest outfall, i.e. 15 East. This was not the case, and although food supply is clearly important and probably responsible for the increases in average individual size other components of the effluent must also be important in structuring these impacted assemblages.

The multivariate methods proved to be very sensitive in detecting differences between locations and treatments for both abundance and biomass data, and also for different transformations and taxonomic levels. These types of multivariate methods are generally recognized as being more sensitive than univariate or descriptive measures for discriminating sites (e.g. Gray et al. 1990, Warwick \& Clark 1991) and they have been recommended as the first stage in data exploration in a monitoring study (Gray et al. 1988). In this study, the Lake Borrie location was clearly different to the other 2 locations despite the broadly similar chemical water quality of all 3 outfalls (Table 1). The 145 West and 15 East locations are separated from the Lake Borrie location by Little River, which may explain the separation on the nMDS plot. The shift of the outfall cores to the same side of the control cores does suggest that there may be similarities in the effects of the transplant to an outfall site at all 3 locations. However, as Keough \& Mapstone (1995) point out, this type of multivariate display is not always easy to interpret biologically, which makes it hard to usefully predict the consequences of continuing exposure to a pollutant.

For the majority of endpoints examined in this study, the direction of change following transplantation to an outfall site, varied across locations even though we were working over a relatively small geographical scale and with chemically similar discharges. We were also unable to predict the responses of various endpoints in relation to each other at all locations using the Pearson \& Rosenberg (1978) conceptual framework. The decreases in abundance and increases in diversity observed in the outfall cores at both 15 East and 145 West locations were unexpected, and there is no starting point on the Pearson \& Rosenberg model that would predict these endpoints to change in this fashion relative to each other. At both these locations, these changes were the result of a reduction in abundance of the numerical dominants and supposedly opportunistic taxa, which served to decrease overall abundance and increase diversity. These types of changes are consistent with those caused by toxic compounds in other soft sediment assemblages (e.g. Olsgard 1993) and again suggest that other components of the effluent such as heavy metals are also important in the structuring of the 'outfall assemblages'. In other parts of the world, predictions about the direction in which certain measures will move can apparently be made with confidence (Ferraro \& Cole 1990, MAFF 1993, Ferraro et al. 1994). In this study, it was not possible to predict how certain endpoints would change in 
relation to each other within a relatively small geographical area.

The scale of this study may explain why the responses of various measures did not always fit with predictions. A lot of studies tend to look for changes across a pollution gradient that may range from unpolluted or background conditions to gross or at least moderately polluted situations. We have undertaken a study that is restricted to a small portion of the pollution gradient and so are looking for more subtle changes when compared to many other studies. We have also sampled on a comparatively fine temporal scale which is not often seen in monitoring studies where it is much more common to sample on a scale of years (e.g. Khan \& Garwood 1995) or months (e.g. Zmarly et al. 1994). Consequently some of the changes we are seeing may form part of a predictable process but are not often observed because of the resolution of the study.

In respect to our original questions, we have found that at the polluted end of an enrichment gradient, fauna can respond very quickly to changes in water quality. To detect subtle improvements or degradation in water quality in already impacted environments monitoring over shorter time frames is recommended. The ability of a variety of measures to detect the effects of impacts varied. The multivariate methods were very sensitive and are highly recommended as a first step in detecting differences between sites. Population level measures tended to be more sensitive than assemblage level measures. While the total biomass/abundance ratio was a sensitive and consistent measure at all locations. The use of more integrated measures such as average individual biomass ( $\mathrm{B}: \mathrm{A}$ ratios) can provide a more sensitive detection tool plus an insight into the biological consequences of the observed changes. In this study, trends in various measures did not necessarily follow expected patterns and differed over a very small geographical distance. Unlike other parts of the world, we found it impossible to predict how, and in what direction, commonly used population or derived assemblage measures will change using general ecological theory and descriptive models.

Acknowledgements. We would like to thank Melbourne Water for allowing us access to the study site and Tom Tomlin for assistance in the field. Sally Woodin provided invaluable advice about running this type of field experiment. Many people helped improve earlier drafts of this manuscript for which we are very grateful and in particular we would like to thank Jan Carey, Peter Morris, Jeremy Hindell and Emma Johnston, Frode Olsgard, Mike Kendall and an anonymous referee for their comments. A Melbourne Research Scholarship supported L.M. during the time of this study.

\section{LITERATURE CITED}

Bat L, Raffaelli D (1998) Sediment toxicity testing: a bioassay approach using the amphipod Corophium volutator and the polychaete Arenicola marina. J Exp Mar Biol Ecol 226:217-239

Bender EA, Case TJ, Gilpin ME (1984) Perturbation experiments in community ecology: theory and practice. Ecology 65:1-13

Bridges TS (1996) Effects of organic additions to sediment, and maternal age and size on patterns of offspring investment and performance in two opportunistic deposit feeding polychaetes. Mar Biol 125:345-357

Bridges TS, Levin LA, Cabrera D, Plaia G (1994) Effects of sediment amended with sewage, algae or hydrocarbons on growth and reproduction in two opportunistic polychaetes. J Exp Mar Biol Ecol 177:99-119

Burd BJ, Nemec A, Brinkhurst RO (1990) The development and application of analytical methods in benthic marine infaunal studies. Adv Mar Biol 26:169-247

Chapman MG (1999) Assessment of variability in responses of intertidal periwinkles to experimental transplantations. J Exp Mar Biol Ecol 236:171-190

Clarke KR (1993) Non-parametric multivariate analyses of changes in community structure. Aust J Ecol 18:117-143

Dauer DM, Conner WG (1980) Effects of moderate sewage input on benthic polychaete populations. Estuar Coast Mar Sci 10:335-346

Davies S, Brown V (1995) Effect of effluent from Western Treatment Plant on benthic biota: monitoring studies 1983-1984. Research Report 16, Melbourne Water PLC, Melbourne

Eleftheriou A, Moore DC, Basford J, Robertson MR (1982) Underwater experiments on the effects of sewage sludge on a marine ecosystem. Neth J Sea Res 16:465-473

Fairweather PG (1991) Statistical power and design requirements for environmental monitoring. Aust J Mar Freshw Res 42:555-567

Ferraro SP, Cole FA (1990) Taxonomic level and sample size sufficient for assessing pollution impacts on the Southern California Bight macrobenthos. Mar Ecol Prog Ser 67: 251-262

Ferraro SP, Cole FA (1995) Taxonomic level sufficient for assessing pollution impacts on the southern California Bight macrobenthos-revisited. Environ Toxicol Chem 14:1031-1040

Ferraro SP, Cole FA, DeBen WA, Swartz RC (1989) Power-cost efficiency of eight macrobenthic sampling schemes in Puget Sound, Washington, USA. Can J Fish Aquat Sci 46:2157-2165

Ferraro SP, Swartz RC, Cole FA, Schults DW (1991) Temporal changes in the benthos along a pollution gradient: Discriminating the effects of natural phenomena from sewage-industrial wastewater effects. Estuar Coast Shelf Sci 33:383-407

Ferraro SP, Swartz RC, Cole FA, DeBen WA (1994) Optimum macrobenthic sampling protocol for detecting pollution impacts in the southern Californian Bight. Environ Monit Assess 29:127-153

Grassle JF, Grassle JP (1974) Opportunistic life histories and genetic systems in marine benthic polychaetes. J Mar Res 32:253-284

Gray JS (1989) Effects of environmental stress on species rich assemblages. Biol J Linn Soc 37:19-32

Gray JS (1992) Biological and ecological effects of marine pollutants and their detection. Mar Poll Bull 25:48-50

Gray JS, Aschan M, Carr MR, Clarke KR, Green RH, Pearson 
TH, Rosenberg R, Warwick RM (1988) Analysis of community attributes of the benthic macrofauna of Frierfjord/Langesundfjord and in a mesocosm experiment. Mar Ecol Prog Ser 46:151-165

Gray JS, Clarke KR, Warwick RM, Hobbs G (1990) Detection of initial effects of pollution on marine benthos: an example from the Ekofisk and Eldfisk oilfields, North Sea. Mar Ecol Prog Ser 66:285-299

Hall SJ, Greenstreet SP (1998) Taxonomic distinctness and diversity measures: responses in marine fish communities. Mar Ecol Prog Ser 166:227-229

Heip C (1995) Eutrophication and zoobenthos dynamics. Ophelia 41:113-136

Keough MJ, Mapstone BD (1995) Protocols for designing marine ecological monitoring programs associated with BEK mills. Technical Report 11. National Pulp Mills Research Program, Canberra

Keough MJ, Quinn GP (1991) Causality and the choice of measurements for detecting human impacts in the marine environment. Aust J Mar Freshw Res 42:539-554

Khan MR, Garwood PR (1995) Long term changes in the benthic macrofauna of the sewage sludge dumping ground off the coast of Northumberland, England. Pak J Zool 27:353-358

Lenihan HS, Kiest KA, Conlan KE, Slattery PN, Konar BH, Oliver JS (1995) Patterns of survival and behaviour in Antarctic benthic invertebrates exposed to contaminated sediments: field and laboratory bioassay experiments. J Exp Mar Biol Ecol 192:233-255

Levin L, Caswell H, Bridges T, DiBacco C, Cabrera D, Plaia G (1996) Demographic responses of estuarine polychaetes to pollutants: life table response experiments. Ecol Appl 6:1295-1313

Maughan JT, Oviatt CA (1993) Sediment and benthic response to wastewater solids in a marine mesocosm. Water Environ Res 65:879-889

Maurer D, Robertson G, Gerlinger T (1993) San Pedro Shelf California: testing the Pearson-Rosenberg model (PRM). Mar Environ Res 35:301-321

Melbourne W (1999) Melbourne Water Corporation Environment and Community Obligation Report 1998/1999

MAFF (UK Ministry of Agriculture, Fisheries and Food Directorate of Fisheries Research) (1993) Analysis and interpretation of benthic community data at sewage-sludge disposal sites. Aquat Environ Mon Rep 37

Morrisey DJ, Underwood AJ, Howitt L (1996) Effects of copper on the faunas of marine soft-sediments: an experimental field study. Mar Biol 125:199-213

Negarestan H (1998) Processes of change in estuarine macrobenthic assemblages. PhD thesis, University of Sydney

Olsgard F (1993) Do toxic algal blooms affect subtidal softbottom communities? Mar Ecol Prog Ser 102:269-286

Olsgard F, Somerfield PJ, Carr MR (1997) Relationships between taxonomic resolution and data transformations in analyses of a macrobenthic community along an established pollution gradient. Mar Ecol Prog Ser 149: 173-181

Olsgard F, Somerfield PJ, Carr MR (1998) Relationships be-

Editorial responsibility: John Gray (Contributing Editor), Oslo, Norway tween taxonomic resolution, macrobenthic community patterns and disturbance. Mar Ecol Prog Ser 172:25-36

Oviatt CA, Quinn JG, Maughan JT, Ellis JT and 6 others (1987) Fate and effects of sewage sludge in the coastal marine environment: a mesocosm experiment. Mar Ecol Prog Ser 41:187-203

Pearson TH, Rosenberg R (1978) Macrobenthic succession in relation to organic enrichment and pollution of the marine environment. Oceanogr Mar Biol Annu Rev 16:229-311

Petch DA (1989) Variation in the spionid polychaete Boccardia proboscidea. PhD thesis, University of Melbourne

Poore GCB, Kudenov JD (1978) Benthos around an outfall of the Werribee sewage-treatment farm, Port Phillip Bay, Victoria. Aust J Mar Freshw Res 29:157-167

Rogers SI, Clarke KR, Reynolds JD (1999) The taxonomic distinctness of coastal bottom-dwelling fish communities of the north-east Atlantic. J Anim Ecol 68:769-782

Somerfield PJ, Olsgard F, Carr MR (1997) A further examination of two new taxonomic distinctness measures. Mar Ecol Prog Ser 154:303-306

Tsutsumi H (1987) Population dynamics of Capitella capitata (Polychaeta; Capitellidae) in an organically polluted cove. Mar Ecol Prog Ser 36:139-149

Tsutsumi H (1990) Population persistance of Capitella sp. (Polychaeta; Capitellidae) on a mud flat subject to environmental disturbance by organic enrichment. Mar Ecol Prog Ser 63:147-156

Underwood AJ (1996) Detection, interpretation, prediction and management of environmental disturbances: some roles for experimental marine ecology. J Exp Mar Biol Ecol 200:1-27

Warwick RM (1986) A new method for detecting pollution effects on marine macrobenthic communities. Mar Biol 92: $557-562$

Warwick RM (1993) Environmental impact studies on marine communities: pragmatical considerations. Aust J Ecol 18: $63-80$

Warwick RM, Clarke KR (1991) A comparison of some methods for analysing changes in benthic community structure. J Mar Biol Assoc UK 71:225-244

Warwick RM, Clarke KR (1995) New 'biodiversity' measures reveal a decrease in taxonomic distinctness with increasing stress. Mar Ecol Prog Ser 129:301-305

Warwick RM, Carr MR, Clarke KR, Gee JM, Green RH (1988) A mesocosm experiment on the effects of hydrocarbon and copper pollution on a sublittoral soft sediment meiobenthic community. Mar Ecol Prog Ser 46:181-191

Washington HG (1984) Diversity, biotic and similarity indices. A review with special reference to aquatic ecosystems. Water Res 18(6):653-694

Weston DP (1990) Quantitative examination of macrobenthic community changes along an organic enrichment gradient. Mar Ecol Prog Ser 61:233-244

Zmarly DI, Stebbins TD, Pasko D, Duggan RM, Barwick KL (1994) Spatial patterns and temporal succession in soft bottom macroinvertebrate assemblages surrounding an ocean outfall on the southern San Diego shelf: relation to anthropogenic and natural events. Mar Biol 118:293-307

Submitted: July 15, 2000; Accepted: May 23, 2001

Proofs received from author(s): January 9, 2002 